\title{
Low-Dose Clozapine for an Adolescent with TBI-Related Fregoli Delusions
}

\section{Ahmed Naguy ${ }^{1 *}$ and Ali Al-Tajali ${ }^{2}$}

${ }^{1}$ Child/Adolescent Psychiatrist, Kuwait Centre for Mental Health (KCMH), Kuwait ${ }^{2}$ General Adult Psychiatrists, Head of Neuromodulation Unit, $\mathrm{KCMH}$, Kuwait

\section{Keywords: TBI; Fregoli delusions; Clozapine}

\section{To The Editor}

Fregoli delusion, first described by Courbon and Fail in 1927, named after an Italian actor Leopoldo Fregoli, is a rare delusional misidentification syndrome which entails that different people are in fact the same person in disguise who is able to change their appearance [1]. It is commonly linked to schizophrenia, schizoaffective disorder, and other organic brain syndromes including head trauma, ischaemic strokes, AD, Parkinson's disease, epilepsy or metabolic derangements [2]. Neurologically, it represents a disconnectivity syndrome of hyperidentification (cf. Capgras) [3]. As TBI sequelae, psychotic symptoms may occur early or late [4]. In the early postinjury period, psychotic symptoms are most commonly manifestations of posttraumatic delirium. In the late postinjury period, these symptoms may be either part of a schizophrenia-like psychosis, comprising predominantly persecutory delusions, auditory hallucinations and dearth of negative symptoms, or be associated features of a mood disorder. The best available epidemiological evidence suggests that TBI confers a modest increased risk for schizophrenia-like psychosis especially if coupled with a positive family history of psychosis and male gender [5]. TBI renders patients more susceptible to neurologic side effects of antipsychotics [6].

Here, we are reporting an adolescent with TBI that later on developed Fregoli delusions. He had supersensitivity to multiple antipsychotic trials with no response at all. When shifted to low-dose clozapine, delusions entirely remitted with great tolerability.

A 15-year-old Palestinian youngster was casualty petitioned in accompaniment of his parents for paranoid ideations of 3 months duration. He is the youngest of 3 sibs emanating from nonconsanguenious monogamous family with no genetic load of neuropsychiatric disorders. Unremarkable developmental trajectories. Distinguished scholastic achievement. No history of smoking or illicit drug use. No medical comorbidities. Had a history of MVA, 10 months ago, incurred severe TBI, admitted to ICU, discharged on prophylactic Valproate $1000 \mathrm{mg} / \mathrm{d}$ for posttraumatic seizures. He was faring well following this accident, as reported by parents, apart from occasional complaints of low-grade headaches and giddiness. Lately, he started to voice out non-sensical talk that the man who hit him by the car is disguising and morphing in the bodies of neighbours, doorkeeper and servants, stalking him in order to kill him. He was panic-stricken by the idea. Fragmented sleep. Lost appetite. Dropped from school attainment. He was seen by a private psychiatrist, a diagnosis of psychotic depression was entertained, and fluoxetine (Prozac $\left.{ }^{\circ}\right) 20 \mathrm{mg}$, olanzapine (Zyprexa") $10 \mathrm{mg}$ and clonazepam (Rivotril') $1 \mathrm{mg}$ were prescribed. He developed severe akathisia. Risperidone was used in lieu. He experienced recurrent torticollis. Quetiapine (Seroquel') was then tried, uptitrated to $600 \mathrm{mg} / \mathrm{d}$. Fluoxetine pushed to $40 \mathrm{mg} / \mathrm{d}$ and clonazepam to $3 \mathrm{mg} / \mathrm{d}$. Sleep improved but the core delusions were untouched after 6 weeks on this combo. He was admitted to our inpatient facility. Thorough laboratory investigations, S. valproate, toxic screen, EEG, neuroimaging were unrevealing. Neuropsychological battery was contemplated and slowing of processing speed, low performance IQ
(80), problems with divided attention were noted. We kept valproate, stopped fluoxetine (self-tapering), gradually tapered quetiapine and clonazepam over 2 weeks. A diagnosis of TBI-related psychosis was our working diagnosis. We introduced clozapine (Leponex), with weekly TLC protocol, at $12.5 \mathrm{mg} / \mathrm{d}$ nocte, uptitrated to $100 \mathrm{mg} / \mathrm{d}$ (divided) over 10 days. No EPS reported. After 2 weeks, Fregoli delusions totally disappeared with no residua. He was discharged. Complete remission continued with follow-ups at W-4, 8, and 12 . BABS was employed throughout to objectify treatment-response on clozapine.

Superiority of clozapine in refractory psychosis is well-established [7]. It has a unique pharmacologic portfolio (Table 1). Clinical use is usually fraught with a myriad of serious adverse drug reactions (Table 2). Apart from dose-dependent seizures, clozapine is almost devoid of neurologic side effects [8]. Impressive response at this relatively low dose is typical of organic psychosis [9].

Clozapine is clearly and unjustifiably underutilized in CAP [10], and we opine that juniors should not be denied a trial of clozapine once refractoriness, according to current guidelines, is established.

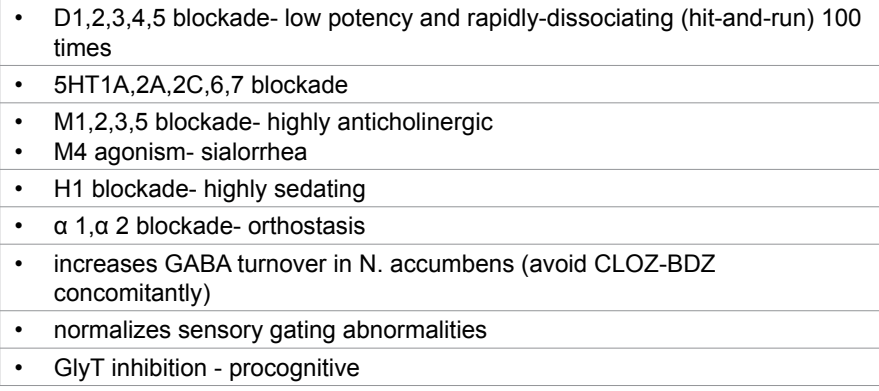

Table 1: Pharmacology of CLOZ.

\begin{tabular}{|ll|}
\hline - & Metabolic syndrome \\
\hline - & Agranulocytosis \\
\hline - & Cardiomyopathy \\
\hline - & Seiuzures \\
\hline - & Orthostasis \\
\hline - & Dementia-related morbidity and mortality \\
\hline & Sialorrhea, constipation \\
\hline
\end{tabular}

Table 2: CLOZ side effects.

*Corresponding author: Ahmed Naguy, Child/Adolescent Psychiatrist, Kuwait Centre for Mental Health (KCMH) CAP department, $\mathrm{KCMH}$, Kuwait, E-mail: ahmednagy@hotmail.co.uk

Received April 25, 2015; Accepted June 13, 2015; Published June 20, 2015

Citation: Naguy A, Al-Tajali A (2015) Low-Dose Clozapine for an Adolescent with TBI-Related Fregoli Delusions. J Psychiatry 18: 306 doi: 10.4172/2378-5756.1000306

Copyright: @ 2015 Naguy A, et al. This is an open-access article distributed under the terms of the Creative Commons Attribution License, which permits unrestricted use, distribution, and reproduction in any medium, provided the original author and source are credited 
Citation: Naguy A, Al-Tajali A (2015) Low-Dose Clozapine for an Adolescent with TBI-Related Fregoli Delusions. J Psychiatry 18: 306 doi: $10.4172 / 2378-5756.1000306$

Page 2 of 2

\section{Abbreviations}

TBI: traumatic brain injury, AD: Alzheimer disease, MVA: motor vehicle accident, ICU: intensive care unit, TLC: total leukocytic count, IQ: intelligence quotient, BABS: Brown assessment of beliefs scale, EPS: extrapyramidal syndromes, CAP: child and adolescent psychiatry, CLOZ: clozapine

\section{References}

1. Langdon R, Connaughton E, Coltheart M (2014) The Fregoli delusion: a disorder of person identification and tracking. Top Cogn Sci 6(4): 615-31.

2. Mojtabai R (1994) Fregoli syndrome. Aust NZ J Psychiatry 28(3): 458-62.

3. Rentrop M, Theml T, Forstl H (2002) Delusional misidentifications. Symptoms and neuropsychological models. Fortschr Neurol Psychiatr 70(6): 313-20.

4. Rao V, Koliatsos V, Ahmed F (2015) Neuropsychiatric disturbances associated with traumatic brain injury: a practical approach to evaluation and management. Semin Neurol 35(1): 64-82

5. Molloy C, Conroy RM, Cotter DR (2011) Is traumatic brain injury a risk factor for schizophrenia? A meta-analysis of case-controlled population-based studies. Schizophr Bull 37(6): 1104-10

6. Mathews M, Gratz S, Adetunji B (2005) Antipsychotic-induced movement disorders: Evaluation and treatment. Psychiatry (Edgmont) 2(3): 36-41

7. Sinclair D, Adams CF(2014) Treatment-resistant schizophrenia: a comprehensive survey of randomized controlled trials. BMC Psychiatry 14: 253

8. Young CR, Bowers MB, Jr, Mazure CM (1998) Management of the adverse effects of clozapine. Schizophrenia Bulletin 24(8): 381-90

9. Meltzer HY(2012) Clozapine: Balancing Safety with Superior Antipsychotic Efficacy. Clinical Schizophrenia \& Related Psychoses 6(3): 134-144.

10. Bobb V, Weinberg M, Gabel S (2013) Use of Clozapine in a State Child and Adolescent Psychiatric Hospital. Psychiatric Quarterly 84(3): 343-349. 